\title{
Surface-Assisted Laser Desorption/Ionization Mass Spectrometry on Titania Nanotube Arrays
}

\author{
Chun-Yuan Lo, Jia-Yi Lin, Wei-Yu Chen, Cheng-Tai Chen, \\ and Yu-Chie Chen \\ Department of Applied Chemistry and Institute of Molecular Science, National Chiao Tung University, \\ Hsinchu, Taiwan
}

Titania nanotube arrays (NTA) generated from anodizing processes are tested as the substrate for surface-assisted laser desorption/ionization mass spectrometry (SALDI MS). The background generated from titania NTA is very low, making the approach suitable for the analysis of small molecules. The upper detectable mass is $\sim 29 \mathrm{kDa}$. Homogeneous sample deposition leads to good shot-to-shot reproducibility and suitability for quantitative analysis. Additionally, phosphopeptides can be selectively trapped on the titania NTA substrate, as illustrated by simply depositing a tryptic digest of $\beta$-casein followed by titania NTA SALDI MS analysis. The detection limit for small organics and peptides is in low fmol. (J Am Soc Mass Spectrom $2008,19,1014-1020)$ (C) 2008 American Society for Mass Spectrometry

$\mathrm{M}$ atrix-assisted laser desorption/ionization mass spectrometry (MALDI MS) has been extensively used in the analysis of different types of analytes since its development [1, 2]. However, employing MALDI MS in the analysis of molecules with a mass of $<600 \mathrm{Da}$ is difficult because of the interference from matrix ions appearing in this mass region. A low background interference in the low mass region is generally obtained when using inorganic materials as the assisting substrate for laser desorption/ionization mass spectrometry. Tanaka et al. [3] first employed nano-sized cobalt powder mixed with glycerol for the analysis of proteins in laser/desorption ionization mass spectrometry. Sunner and coworkers [4] alternatively used micro-sized carbon materials such as graphite and active carbon powder [5-8] mixed with glycerol for the analysis of peptides and proteins in laser/desorption ionization mass spectrometry. This was named as surfaceassisted laser desorption/ionization mass spectrometry (SALDI MS) because the surface structure was critical to obtaining mass spectra $[9,10]$. Furthermore, the enhanced surface area and altered electric and thermal properties $[9,10]$ also affect the SALDI mass spectral results. Low matrix background and homogeneous sample deposition are the characteristics of SALDI MS analysis. Many effective SALDI-assisted materials [1139] have also been discovered since the development of SALDI MS. For example, inorganic materials such as pencil lead [11], carbon nanotubes [12-14], and metal oxide powders $[15,16,21,22]$ have been demonstrated to be useful SALDI substrate.

Address reprint requests to Dr. Y.-C. Chen, Department of Applied Chemistry and Institute of Molecular Science, National Chiao Tung University, 1001 Ta Hsueh Road, Hsinchu 300, Taiwan. E-mail: yuchie@mail.nctu.edu.tw
Nanoparticles, not only of cobalt but also of gold [23-25], have been demonstrated to be effective SALDI assisted materials for the analysis of small organics such as aminothiols [24] and saccharides [25]. Additionally, desorption ionization from porous silicon substrate (DIOS) [26] has attracted a great deal of attention because of its suitability for the analysis of small organics with low background interference. Thus, most of these studies have addressed the suitability of these approaches to the analysis of small analytes.

When using sol-gel derived 2,5-dihydroxybenzoic acid (DHB) [27-30] as the SALDI substrate, not only can the absence of background interference in the mass spectra when analyzing small organics be observed but the detectable mass range can also be extended to $>10$ $\mathrm{kDa}$. To make the fabrication of sol-gel films easier, titania films capable of absorbing laser energy in the ultraviolet (UV) region were then proposed to be used as the SALDI substrate [31, 32]. The detectable mass range was further extended to $\sim 24 \mathrm{kDa}$. Alternatively, the titania substrate can easily be generated from titanium sheets via electrochemical etching. Effective DIOS [26] and SALDI substrates [10] have been generated from electrochemical approaches. Although porous silicon can readily be generated from silicon wafer via electrochemical etching and directly used for DIOS analysis, [26] the etched silicon substrate is easily oxidized and becomes ineffective. Etched alumina sheets can be generated from an anodizing process. However, sputtering a layer $(50 \mathrm{~nm})$ of $\mathrm{Au}$ and $\mathrm{Pt}$ onto the alumina sheet is required for obtaining improved SALDI MS results. We believe that this approach can be simplified by directly etching titanium into titanium dioxide, which is capable of absorbing ultraviolet laser, via electrochemical etching. Therefore, the etched substrate can readily be used for SALDI MS analysis 
without the requirement of sputtering a layer of metal on the anodized substrate. The time required for the preparation of the SALDI substrate can then be reduced. Furthermore, titania is quite stable at ambient condition. After anodizing processes [40], titania nanotube arrays (NTAs) are generally formed. We found that background interference was almost absent in the titania NTAs during laser desorption/ionization. When titania films are used as the SALDI substrates, $\mathrm{Ti}_{\mathrm{x}} \mathrm{O}_{\mathrm{y}}$ ions may occasionally contribute to the SALDI mass spectra [31, 32]. However, these $\mathrm{Ti}_{\mathrm{x}} \mathrm{O}_{\mathrm{y}}$ ions do not appear in the titania NTA-SALDI mass spectra, so a clean window in the low mass region is obtained. This feature suggests its suitability for the analysis of small organics. Furthermore, because of titania's unique feature of binding with phosphopeptides, the selective enrichment of phosphopeptides directly on a titania NTA sheet followed by titania NTA-SALDI MS analysis is also demonstrated in this study.

\section{Experimental}

\section{Reagents and Materials}

Titanium sheets (0.127 mm thick, $99.7 \%$ purity) were obtained from Aldrich (Steinheim, Germany), while 3-hydroxytyramine hydrochloride, melittin, polyethylene glycol (MW $\left.{ }_{\text {ave }} 600\right)$, graphite powder $(1 \sim 2 \mu \mathrm{m})$, and tetraethoxysilane (TEOS) were obtained from Fluka (Buchs, Switzerland). Bradykinin, insulin, ubiquitin, cytochrome $c$, myoglobin, trypsinogen, carbonic anhydrase, citric acid, $\beta$-casein, glucose, and trypsin (from bovine pancreas) were obtained from Sigma (St. Louis, MO). Hexadecyltrimethylammonium bromide (CTAB), diammonium hydrogen citrate, trifluoroacetic acid (TFA), phosphoric acid, glucose, and ammonium bicarbonate were purchased from Riedel-de Haën (Seelze, Germany). Methanol and hydrogenfluoric acid (HF) were obtained from Tedia (Fairfield, OH). Hydrochloric acid and nitric acid were purchased from J. T. Baker (Phillipsburg, MO). Acetonitrile was obtained from Merck (Darmstadt, Germany), and ethanol from Showa (Tokyo, Japan). Titanium(IV) n-butoxide and nitric acid were obtained from Acros (Morris Plains, NJ). Silicon wafers (P/boron type, $<100>$ orientation, low resistivity (ca. $0.0095 \sim 0.013 \Omega \mathrm{cm}$ ), 500 550 $\mu \mathrm{m}$ thick, and 99.5 100.5 $\mathrm{mm}$ in diameter) were purchased from Sino-American Silicon Products Inc. (Hsinchu, Taiwan). Blood plasma was donated by a healthy volunteer, while the double-sided black carbon tape was purchased from Ted Pella (Redding, CA).

\section{Preparation of Titania NTA Substrate}

Titanium sheets $(4 \mathrm{~cm} \times 1.5 \mathrm{~cm})$ were rinsed with ethanol and acetone with sonication before anodizing treatment. The anodization of the titanium sheet was carried out using a DC power supply (Human Dual Tracking, Taiwan). The DC voltage was set at $20 \mathrm{~V}$, while the time for anodization was $20 \mathrm{~min}$. The sheet was rapidly removed from the electrolyte $(0.5 \% \mathrm{HF})$ after anodization and was rinsed with deionized water followed by drying with a hair dryer. Subsequently, the sheet was put in an oven at $500{ }^{\circ} \mathrm{C}$ for $1 \mathrm{~h}$ and rinsed by methanol before use.

\section{Titania NTA-SALDI MS Analysis}

Because the titania NTA sheet obtained above was very hydrophilic, we stamped small $\mathrm{SiO}_{2}$ loops (diameter 2 or $3 \mathrm{~mm}$ ) by using $\mathrm{SiO}_{2}$ sol as the plaster on the sheet to create a small ring for restraining the samples within it. The $\mathrm{SiO}_{2}$ sol was prepared by stirring aqueous hydrochloric acid $(0.37 \%, 0.5 \mathrm{~mL})$, deionized water $(1 \mathrm{~mL})$, and TEOS ( $4.5 \mathrm{~mL})$ for $24 \mathrm{~h}$. The sheet was allowed to dry at room temperature for $15 \mathrm{~min}$, and it was adhered on a MALDI target by a double-sided carbon tape before the samples were deposed. The analytes with molecular masses $<1000$ Da were prepared in water or proper solvents, while the analytes with molecular masses $>1000$ Da were mixed with an equal volume of citrate solution containing citric acid (50 mM) and ammonium citrate (50 $\mathrm{mM}$ ). Then, $0.5 \mu \mathrm{L}$ of the sample was deposited on the $\mathrm{SiO}_{2}$ loop on the titania sheet. After evaporation of the solvent, the sample was ready for MS analysis.

\section{Quantitative Analysis of Glucose from Blood Plasma}

Blood plasma was diluted tenfold with deionized water, and the molecules $>10 \mathrm{kDa}$ were removed by a filter (Microcon YM-10 centrifugal filter) under centrifugation at 13,000 $\mathrm{g}$ for $30 \mathrm{~min}$. Quantitative analysis was performed using the standard addition method. That is, the supernatant obtained above was added with given amounts of glucose and then spiked with CTAB $(4.34 \times$ $\left.10^{-8} \mathrm{M}\right)$ as the internal standard. The plasma samples $(0.3 \mu \mathrm{L})$ spiked with CTAB were deposited onto the loops generated on a titania NTA sheet for SALDI MS analysis. A calibration curve was obtained by plotting the ratio of the peak area's sum at $m / z 203$ and 219 to the peak area at $m / z 284$ as a function of the concentration of spiked glucose.

\section{On-Sheet Selective Enrichment of Phosphopeptides from the Tryptic Digest of $\beta$-Casein}

$\beta$-Casein $(2 \mathrm{mg} / \mathrm{mL}, 500 \mu \mathrm{L})$ and trypsin $(2 \mathrm{mg} / \mathrm{mL}, 10$ $\mu \mathrm{L})$ prepared in aqueous ammonium bicarbonate (50 $\mathrm{mM}$ ), at a weight ratio of $50: 1$, were incubated at $37^{\circ} \mathrm{C}$ for $18 \mathrm{~h}$. The tryptic digest was diluted to $5 \times 10^{-5} \mathrm{M}$. The digest $(5 \mu \mathrm{L})$ was acidified by diluting in $0.15 \%$ TFA solution $(45 \mu \mathrm{L})$, then $0.5 \mu \mathrm{L}$ of the acidified solution was deposited on a $\mathrm{SiO}_{2}$ loop on the titania NTA sheet. After standing at ambient for $5 \mathrm{~min}$, the sample on the sheet was rinsed with $0.15 \%$ TFA prepared in the solvent of acetonitrile/deionized (1/1, $\mathrm{vol} / \mathrm{vol})(0.5 \mathrm{~mL} \times 2)$ to remove nonphosphopeptides. 
After evaporation of the solvent, $0.5 \mu \mathrm{L}$ of the mixture of citric acid $(25 \mathrm{mM})$ and ammonium citrate $(25 \mathrm{mM})$ was applied onto the same loop. The sample was introduced into the MALDI mass spectrometer for analysis after the solvent evaporated.

\section{Fabrication of Porous Silicon Chips}

Porous silicon chips were fabricated using the method reported previously [41]. A silicon wafer was soaked in a solution of $\mathrm{H}_{2} \mathrm{SO}_{4} / \mathrm{H}_{2} \mathrm{O}_{2}$ (3:1, vol:vol) for $30 \mathrm{~min}$. The wafer was rinsed with ethanol and dried under nitrogen gas. The wafer was then anodically etched in a $24 \%$ hydrofluoric acid in ethanol. A current density of 100 $\mathrm{mA} \mathrm{cm}{ }^{-2}$ was applied for $30 \mathrm{~min}$. The etched wafer was rinsed with ethanol and stored in ethanol before use.

\section{Preparation of Titania Sol-Gel films}

Titania sol-gel films were fabricated using the procedure reported elsewhere [32]. Briefly, titania sol was prepared by stirring titanium(IV) $n$-butoxide $(3.4 \mathrm{~mL}$ ) and ethanol $(1.6 \mathrm{~mL})$ for $30 \mathrm{~min}$ at room temperature (ca. $\left.27^{\circ} \mathrm{C}\right)$. A solution of ethanol $(1.6 \mathrm{~mL})$, water $(0.18$ $\mathrm{mL})$, and $60 \%$ nitric acid $(75 \mathrm{~mL})$ was then added slowly into the titanium(IV) $n$-butoxide/ethanol solution, which was stirred for an additional $10 \mathrm{~min}$ in an ice bath. Polyethylene glycol ( $\left.\mathrm{MW}_{\text {ave }} 600,15 \mathrm{~g}\right)$ was added into the mixture and stirred for ca. $30 \mathrm{~min}$ in a water bath maintained at $40{ }^{\circ} \mathrm{C}$. An aluminum sheet $(2 \mathrm{~cm} \times 2 \mathrm{~cm} \times 0.2$ $\mathrm{mm}$ ) was used as the support for the titania sol coating. The aluminum support was pretreated by soaking it in acetone and then in methanol for $5 \mathrm{~min}$ in a sonicator to remove impurities. The titania sol solution was spincoated onto the surface of the aluminum support using a spin coater. The titania sol solution was applied slowly to the aluminum sheet during the spin-coating process. The modified aluminum sheet, coated with a thin film of titania, was aged for $20 \mathrm{~min}$ at room temperature. This titania chip was calcinated at $500{ }^{\circ} \mathrm{C}$ for $1 \mathrm{~h}$.

\section{Instrumentation}

All the mass spectra were obtained from a Bruker Biflex III MALDI-TOF MS (Leipzig, Germany). The SEM images were obtained using a Hitachi S-4700I scanning electron microscope (Japan).

\section{Results and Discussion}

Figure $1 \mathrm{a}$ and $\mathrm{b}$ show the top view and the side view of the titania NTAs that were generated from anodization, respectively. The inside and outside diameters of the tubes are ca. $70 \mathrm{~nm}$ and ca. $120 \mathrm{~nm}$, respectively, while the length of the tubes is ca. $250 \mathrm{~nm}$. Figure $1 \mathrm{c}$ shows the top view of the same array that has been heated at $500{ }^{\circ} \mathrm{C}$ for $1 \mathrm{~h}$. The morphology looks similar to that obtained before calcination. When the titania NTAs
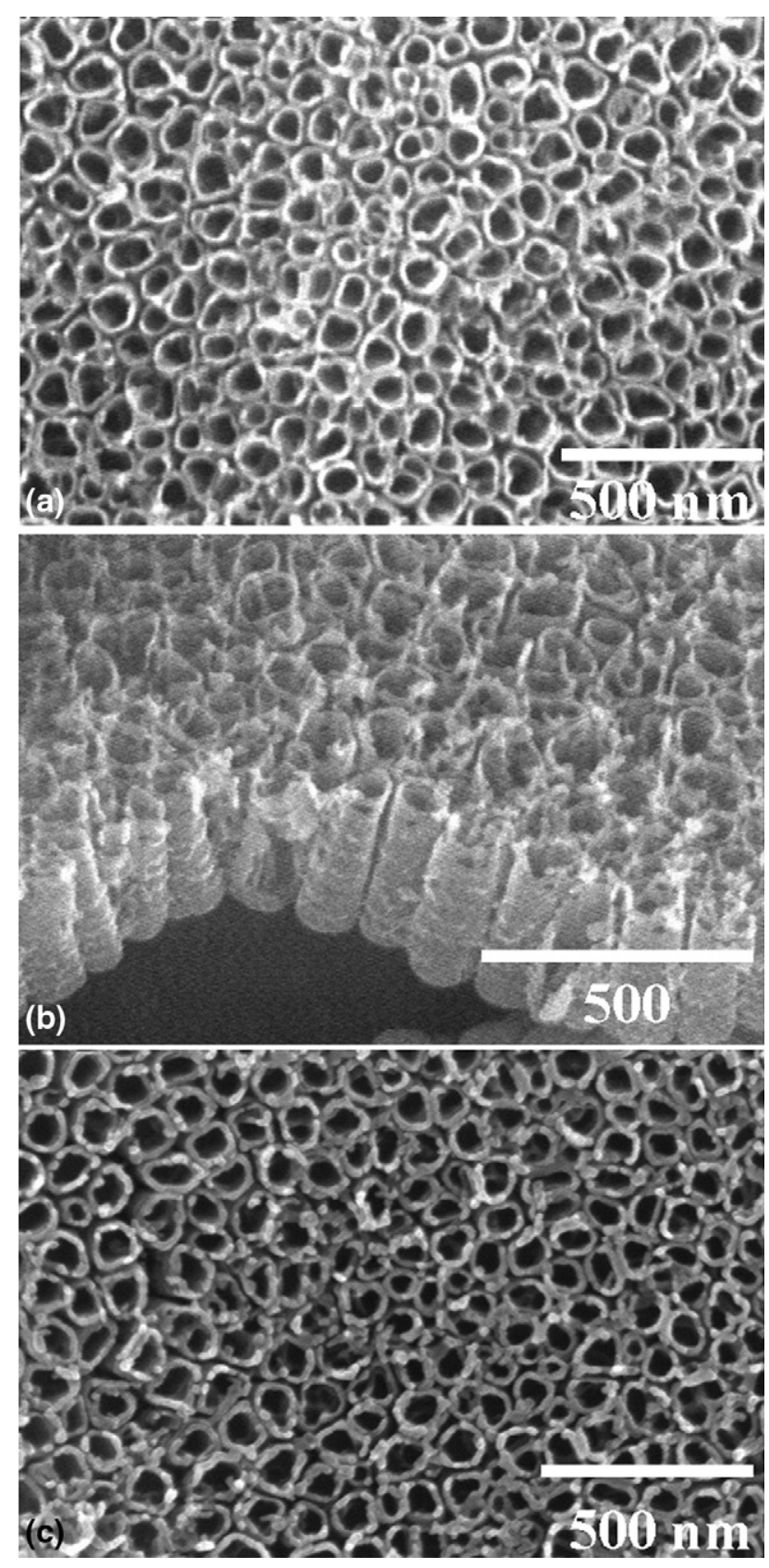

Figure 1. SEM images of the (a) top view and (b) side view of a titania-NTA sheet. (c) SEM image of the top view a titania-NTA sheet that has been calcinated at $500{ }^{\circ} \mathrm{C}$ for $1 \mathrm{~h}$.

were irradiated with a UV laser, only two ions at $m / z 23$ and 39 corresponding to sodium and potassium ions, respectively, appear in the mass spectrum (Figure 2a). As the laser power was increased, there were still no any other ions observed in the SALDI mass spectra. The results demonstrate that titania NTA-SALDI MS can provide nearly free of background interference even operated at a high laser power. This phenomenon is rarely observed because the background ions derived from other types of inorganic substrate generally appear as the laser energy is increased, based on our experience. Presumably, the inorganic structure formed 


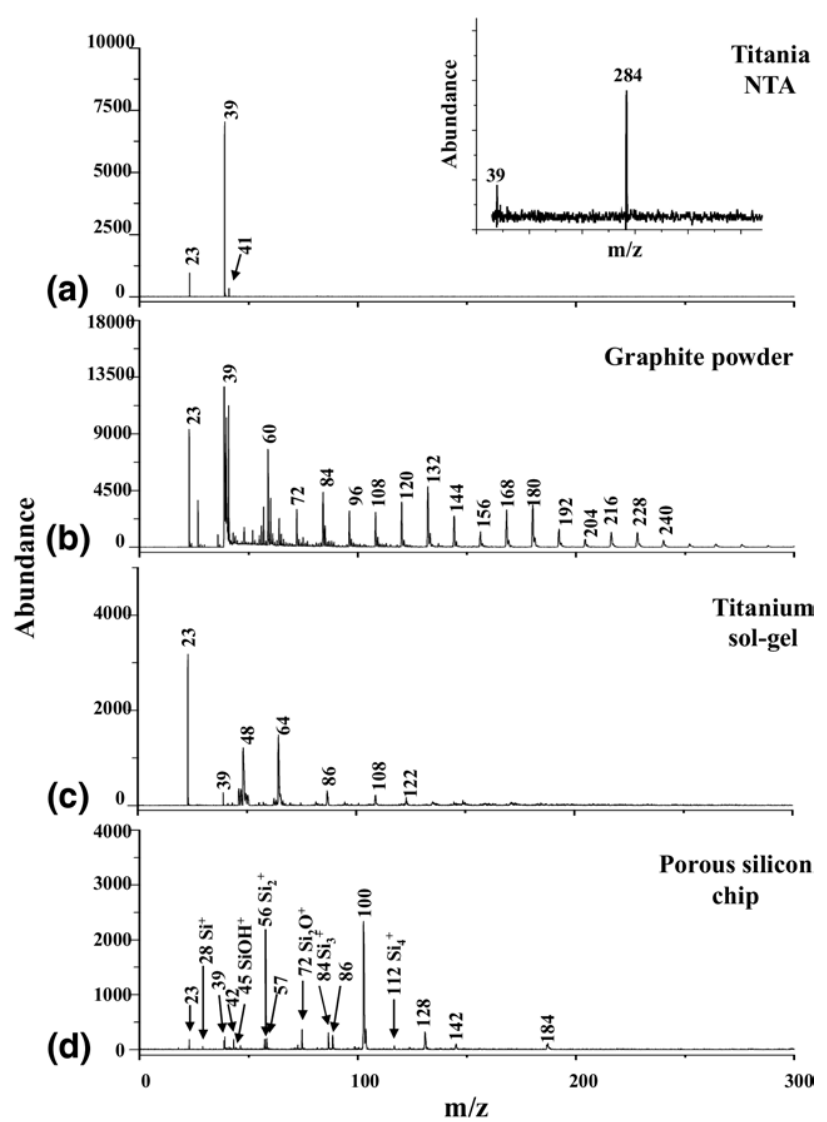

Figure 2. Direct laser desorption mass spectra of (a) titania NTA substrate, (b) graphite powder, (c) a titania sol-gel film (d), a porous silicon chip obtained without depositing with any samples. The laser attenuation (atten) for obtaining each mass spectrum above was adjusted to 18 . The inset in (a) presents the titania NTA SALDI mass spectrum of CTAB $\left(10^{-7} \mathrm{M}, 0.5 \mu \mathrm{L}\right)$. The laser attenuation is set on 39. All the mass spectra were obtained from 100 laser shots.

by this approach is quite rigid, which results in difficult desorption during laser irradiation. Since there is almost an absence of background interference in the titania NTA-SALDI mass spectra, we further employed this approach to the analysis of small organics. The inset in Figure 2a presents a titania-NTA SALDI mass spectrum of CTAB $\left(10^{-7} \mathrm{M}, 0.5 \mu \mathrm{L}\right)$. The peak at $\mathrm{m} / z 284$ is derived from a cation of CTAB due to the loss of a bromide ion. For comparison, we employed the same laser power to irradiate graphite, titanium sol-gels, and a porous silicon chip. In addition to sodium and potassium ions, a series of carbon cluster ions with a 12 mass-unit difference derived from graphite appear in Figure $2 \mathrm{~b}$. Figure $2 \mathrm{c}$ displays the laser desorption (LD) mass spectrum of the titania sol-gel film. Sodium and potassium ions at $m / z 23$ and 39 , respectively, are still visible in the mass spectrum. The peaks at $m / z 48$ and 64 correspond to $\mathrm{Ti}^{+}$and $\mathrm{TiO}^{+}$, respectively. Figure $2 \mathrm{~d}$ shows the LD mass spectrum of the porous silicon chip, which was fabricated based on the procedure present in a DIOS paper [41]. However, we did not further coat polymers on the surface after etching the chip because we tried to make the procedure similar to our current fabrication method for titania NTAs. Sodium and potassium ions still appear in the mass spectrum. A peak at $m / z 100$, which is not identified, dominates the mass spectrum. Furthermore, the ions at $m / z 28,45,56,72,84$, and 112 corresponding to $\mathrm{Si}^{+}, \mathrm{SiOH}^{+}, \mathrm{Si}_{2}{ }^{+}, \mathrm{Si}_{2} \mathrm{O}^{+}, \mathrm{Si}_{3}{ }^{+}$, and $\mathrm{Si}_{4}{ }^{+}$, respectively, which were observed in a previous study [37], appear in the same mass spectrum. The rest of ions are unable to be identified. Presumably, they were derived from the organics existing in ambient and were trapped by the porous silicon chip. On the basis of above results, titania NTA substrate provides less background interference under laser irradiation than the rest of substrates. Furthermore, even the laser power is further increased, only sodium and potassium ions appear in the titania-NTA SALDI mass spectra (results not shown).

We further investigated the feasibility of using this approach in quantitative analysis for small organics. Titania-NTA SALDI MS was used to determine the concentration of glucose from a blood plasma sample. A cationic surfactant, CTAB, was used as the internal

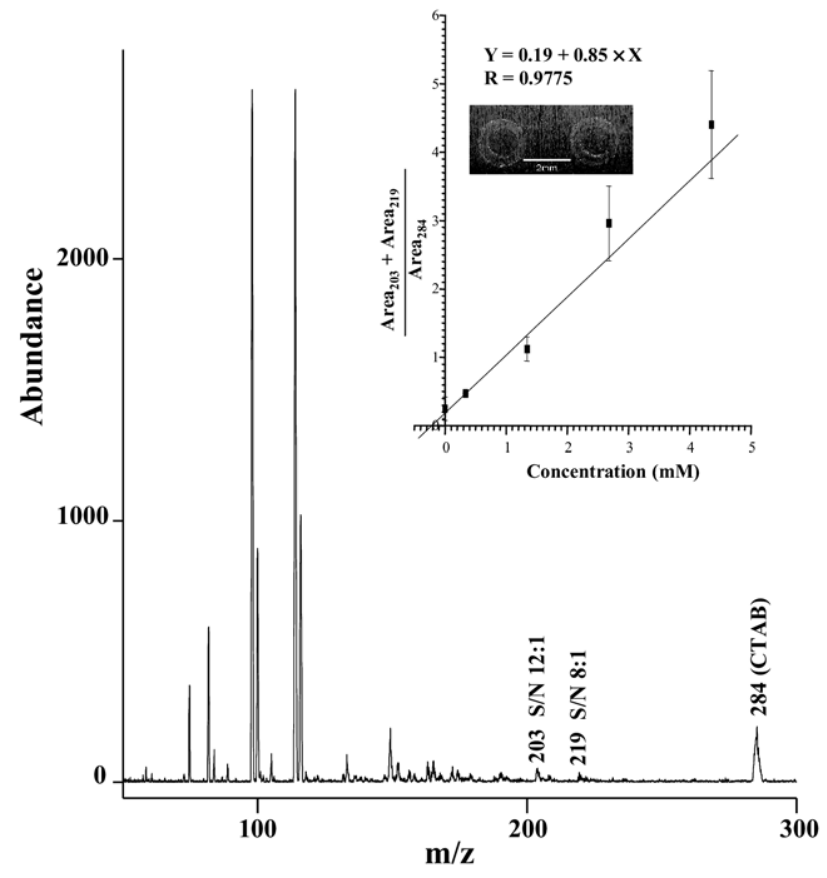

Figure 3. Titania-NTA SALDI mass spectrum of a diluted human plasma $(0.3 \mu \mathrm{L})$ which was spiked with CTAB $\left(4.34 \times 10^{-8}\right.$ $\mathrm{M})$. The blood plasma was initially diluted tenfold by deionized water, and the molecules $>10 \mathrm{kDa}$ were removed by a filter under centrifugation at $13,000 \mathrm{~g}$ for $30 \mathrm{~min}$. The inset is the calibration curve obtained using a standard addition method. The standard solutions were prepared by adding $0,5,20,40$, and $65 \mu \mathrm{L}$ of glucose $(7.7 \mathrm{mM})$ to the plasma samples $(45 \mu \mathrm{L})$. CTAB $\left(10^{-6} \mathrm{M}, 5\right.$ $\mu \mathrm{L}$ ) was added to each standard solution. Each standard solution was diluted to $115 \mu \mathrm{L}$ with deionized water. The inset calibration curve was obtained by plotting the ratio of the sum of the peak area at $m / z 203\left(\left[\right.\right.$ glucose $\left.\left.+\mathrm{Na}^{+}\right]\right)$and $219\left(\right.$ [glucose $+\mathrm{K}^{+}$]) to the peak area at $\mathrm{m} / \mathrm{z} 284$ (CTAB). The inset in the calibration curve is the photograph of a titania-NTA sheet stamped with $\mathrm{SiO}_{2}$ loops (diameter: $2 \mathrm{~mm}$ ). No citrate salts were added in these samples. 
standard. CTAB is a precharged ion, so its presence in the sample should have a negligible effect on the ionization of other molecules present in the sample. The peaks at $m / z 203$ [at a signal-to-noise (S/N) of 12] and 219 (S/N 8:1) derived from sodium and potassium adducts of glucose, respectively, appear in the mass spectrum (Figure 3 ). In addition to these two peaks, there are many peaks derived from the plasma present in the same mass spectrum. The inset presents the photograph of the titania-NTA sheet stamped with $\mathrm{SiO}_{2}$ loops, which are used to restrict the sample inside. The sample is deposited in the loop. To reduce the interference effect in quantitative analysis, we employed the standard addition method to generate a calibration curve for glucose. The calibration curve is shown as the inset. The equation of the calibration curve is $Y=0.19+0.85 \times$ $X$ and the correlation coefficient is ca. 0.9775 . The concentration of glucose in the 25.5-fold diluted blood plasma was estimated ca. $0.22 \mathrm{mM}$ based on this equation. Therefore, the concentration of blood glucose was ca. $5.61 \mathrm{mM}$, which is in the normal range of human blood [42]. The results indicated that this approach is potentially suitable for the quantitative determination of the amount of small organics from complex samples.

In addition to small organics, we also explored the use of the titania-NTA SALDI MS approach in the analysis of biomolecules such as peptides and small proteins. For comparison, we first used a titanium film before anodization as the assisted substrate for SALDI MS analysis. Figure 4a shows the titanium-SALDI mass spectrum of melittin. A broad peak derived from the protonated pseudomolecular ion of melittin [mass resolution $(\mathrm{R})=429 ; \mathrm{S} / \mathrm{N}$ 42:1] appears in the SALDI mass spectrum. However, when the titania NTA is used as the SALDI substrate for the SALDI MS analysis of bradykinin, a sharp peak at $\mathrm{m} / \mathrm{z} 2847(\mathrm{R}=990 ; \mathrm{S} / \mathrm{N}$ 93:1) appears in the mass spectrum (Figure $4 b)$. Further-

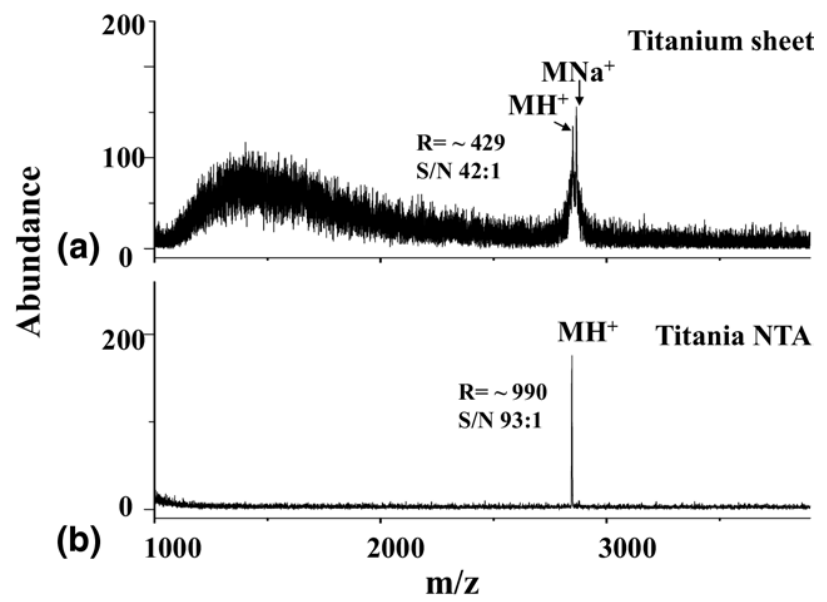

Figure 4. (a) Titanium-SALDI mass spectrum of melittin $(5 \times$ $10^{-6} \mathrm{M}, 0.5 \mu \mathrm{L}$ ). (b) Titania-NTA SALDI mass spectrum of melittin $\left(5 \times 10^{-6} \mathrm{M}, 0.5 \mu \mathrm{L}\right)$. The melittin sample contained citric acid (50 $\mathrm{mM})$ and ammonium citrate $(50 \mathrm{mM})$. The samples were deposited onto $\mathrm{SiO}_{2}$ loops (diameter: $3 \mathrm{~mm}$ ).

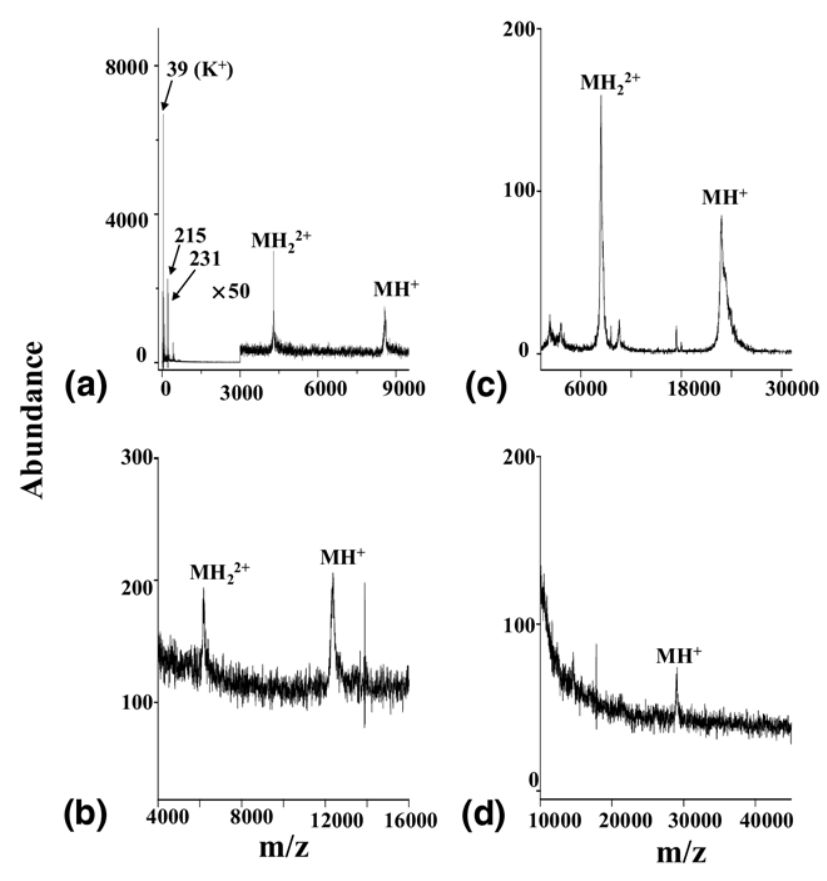

Figure 5. Titania-NTA SALDI mass spectra of (a) ubiquitin $(5 \times$ $\left.10^{-6} \mathrm{M}, 0.5 \mu \mathrm{L}\right),(\mathbf{b})$ cytochrome $c\left(5 \times 10^{-6} \mathrm{M}, 0.5 \mu \mathrm{L}\right)$, (c) trypsinogen $\left(4 \times 10^{-6} \mathrm{M}, 0.5 \mu \mathrm{L}\right)$, and (d) carbonic anhydrase $\left(10^{-4} \mathrm{M}, 0.5 \mu \mathrm{L}\right)$. Citric acid $(50 \mathrm{mM})$ and ammonium citrate (50 $\mathrm{mM}$ ) were present in these samples. The samples were deposited onto $\mathrm{SiO}_{2}$ loops (diameter: $3 \mathrm{~mm}$ ).

more, its sodium adducts disappear. Citrate salts were added in both samples for rending the protonation of melittin. The results indicate that using the titania NTA sheet derived from anodization as the SALDI assisted material is helpful for improving the SALDI MS analysis. To examine the shot-to-shot reproducibility, we used bradykinin as the sample and examined its reproducibility in titania NTA-SALDI mass spectra. The relative standard deviation (RSD) of the ion abundance of protonated bradykinin (47 pmol) at $\mathrm{m} / \mathrm{z} 1061$ for the shot-to-shot reproducibility was estimated ca. $10 \%$.

We further investigated the feasibility of using titania NTA-SALDI MS for larger analytes. Figure 5a-d presents the titania-NTA SALDI mass spectra of ubiquitin $\left(5 \times 10^{-6} \mathrm{M}, 0.5 \mu \mathrm{L}\right)$, cytochrome $c\left(5 \times 10^{-6} \mathrm{M}, 0.5\right.$ $\mu \mathrm{L})$, trypsinogen $\left(4 \times 10^{-6} \mathrm{M}, 0.5 \mu \mathrm{L}\right)$, and carbonic anhydrase $\left(10^{-4} \mathrm{M}, 0.5 \mu \mathrm{L}\right)$, respectively. Although a higher laser power is required to analyze these proteins, the background is extremely clean. Sodium and potassium ions still dominate the mass spectrum in Figure 5a. Two more peaks at $\mathrm{m} / \mathrm{z} 215$ and 231 corresponding to sodium and potassium adduct ions of citric acid, which was added to utilize the ionization for analytes, appear in the same mass spectrum. Although the baseline seems upward in the mass spectra of Figure $5 b$ and $d$, there are no additional ions appearing in the mass spectra. The protonated pseudomolecular ions $\left(\mathrm{MH}^{+}\right)$ of the analytes appear in all the mass spectra. Furthermore, the doubly charged ions $\left(\mathrm{MH}_{2}^{2+}\right)$ of the proteins with molecular mass $>5000$ Da become noticeable in 
the mass spectra. The upper detectable mass is as high as $\sim 29 \mathrm{kDa}$, although the mass resolution becomes poorer as the molecular size becomes larger. Nevertheless, to the best of out knowledge, the upper detectable mass is the highest that has ever been reported using inorganic materials as the SALDI substrate without the presence of liquid glycerol.

The detection limit for bradykinin (S/N 4:1) is ca. 78 fmol in the absence of citric salts when titania-NTAs are used as the SALDI substrate. On the basis of our experience, adding citrate salts to the SALDI sample is helpful for rendering the ionization efficiency of the analytes with molecular masses $\geq 1000 \mathrm{Da}$. The detection limit of bradykinin (S/N 4:1) in titania-NTA SALDI MS is lowered to $6 \mathrm{fmol}$ in the presence of citrate salts. We also examined the detection limit and upper mass limits by using various types of SALDI substrates for SALDI MS analysis with the addition of citrate salts. Table 1 lists the detection limit (S/N 4:1) of bradykinin and upper mass limit obtained by using various types of SALDI substrates for SALDI MS analysis. All the results were obtained under the optimal condition. The results indicate that the detection limit using titania NTA as the SALDI substrate is slightly higher than that using porous silicon chips as the SALDI substrate for SALDI MS analysis. Nevertheless, the upper mass limit of our titania NTA SALDI MS is the highest among these SALDI substrates. The upper mass limits using titania-NTA, titania sol-gels, graphite, and porous silicon chips as the SALDI substrate for SALDI MS analysis are ca. $29 \mathrm{kDa}$ (carbonic anhydrase), ca. $24 \mathrm{kDa}$ (trypsinogen), ca. $12.3 \mathrm{kDa}$ (cytochrome $c$ ), and ca. 5.7 $\mathrm{kDa}$ (insulin), respectively.

It has been previously demonstrated that titania materials are capable of selectively trapping phosphopeptides from a peptide mixture [16]. Thus, we examined this possibility by selectively trapping phosphopeptides from a tryptic digest of $\beta$-casein $(0.5 \mu \mathrm{L})$ directly from the titania NTA sheet. After the sample was deposited on a titania NTA substrate and allowed to stand at ambient for $5 \mathrm{~min}$, the sample on the substrate was rinsed with $0.15 \%$ TFA solution to remove unbound species. Figure 6a presents the direct titania-NTA SALDI mass spectrum of the tryptic digest of $\beta$-casein before removal of unbound species. All the peaks appearing in the mass spectrum are not phosphopeptides. However, when washing procedures

Table 1. Comparisons of various types of SALDI substrates for SALDI MS analysis in terms of detection limit and upper mass limit

\begin{tabular}{lcc}
\hline \multicolumn{1}{c}{ SALDI substrate } & Detection limit $^{\mathrm{a}}$ & Upper mass limit \\
\hline \hline Titania NTAs & $6 \mathrm{fmol}$ & $29 \mathrm{kDa}$ \\
Titania sol-gels & $7 \mathrm{fmol}$ & $24 \mathrm{kDa}$ \\
Graphite & $66 \mathrm{fmol}$ & $12 \mathrm{kDa}$ \\
Porous silicon chips & $2 \mathrm{fmol}$ & $5.7 \mathrm{kDa}$ \\
\hline
\end{tabular}

${ }^{a}$ The detection limit of bradykinin was determined in terms of a signal to noise ratio of 4 .

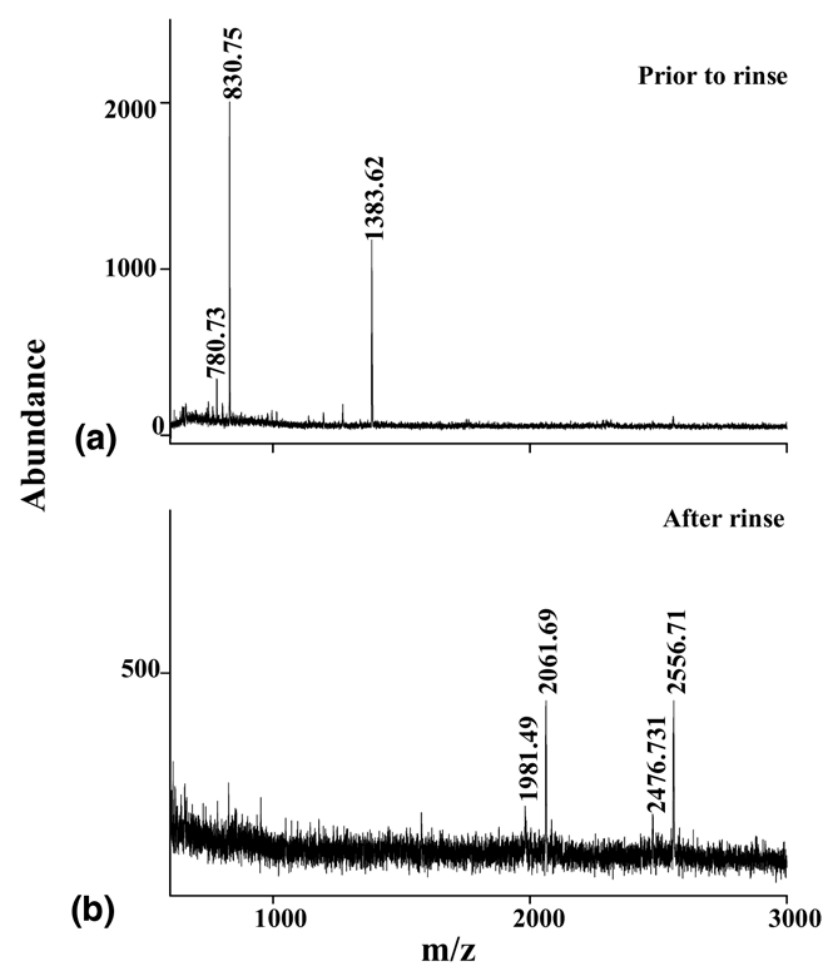

Figure 6. (a) Direct titania-NTA SALDI mass spectrum of the tryptic digest of $\beta$-casein $\left(5 \times 10^{-6} \mathrm{M}, 0.5 \mu \mathrm{L}\right)$ before rinse. (b) Titania-NTA SALDI mass spectrum of the tryptic digest of $\beta$-casein $\left(5 \times 10^{-6} \mathrm{M}, 0.5 \mu \mathrm{L}\right)$ after rinse. The samples were deposited in $\mathrm{SiO}_{2}$ loops. After evaporation of the rinse solvent $(0.15 \%$ TFA prepared in the solvent of acetonitrile/deionized $(1 / 1, \mathrm{vol} / \mathrm{vol})$, $0.5 \mu \mathrm{L}$ of the mixture of citric acid $(25 \mathrm{mM})$ and ammonium citrate $(25 \mathrm{mM})$ was applied onto the same loop (diameter: $3 \mathrm{~mm}$ ). After evaporation of the solvent, the sample was introduced into the mass spectrometer.

were carried out on the titania-NTA sheet after the deposition of the digest sample, phosphopeptides started to appear in the titania-NTA SALDI mass spectrum. Figure $6 \mathrm{~b}$ displays the titania-NTA SALDI mass spectrum of the tryptic digest of $\beta$-casein after on-sheet selective-enrichment. The peaks at $\mathrm{m} / \mathrm{z}$ 2061.69 (FQsEEQQQTEDELQDK [\#33-48]), "s" stands for phosphorylated serine) and 2556.71 (FQsEEQQQTEDELQDKIHPF [\#33-52]) are phosphopeptides derived from $\beta$-casein, while the peaks at $\mathrm{m} / \mathrm{z}$ 1981.49 and 2476.73 are their corresponding fragments due to the loss of a $\mathrm{HPO}_{3}^{-}$, respectively. There are no nonphosphopeptides appearing in the mass spectrum. The results indicate that our titania-NTA substrate fulfills two roles, namely both as an affinity substrate for phosphopeptides and as a SALDI substrate.

\section{Conclusions}

The use of titania NTAs for SALDI MS analysis is reported for the first time. The procedures for fabrication of the titania NTAs are extremely simple. Although the etching procedures of our approach and the time for fabrication of the titania NTA substrate are similar to 
those for porous silicon chips, the titania NTA substrate is quite stable at ambient condition. Furthermore, the titania NTAs are ready for use as the SALDI substrate without requiring any further modifications after etching. Thus, the advantages of using titania-NTA as the SALDI substrate involve ease of manufacture, ease of handling, low background interference, and stability. We believe that the titania NTAs can potentially become a suitable SALDI substrate for practical uses after extensive studies.

\section{Acknowledgments}

The authors thank the National Science Council (NSC) of Taiwan and MOE-ATU (96W821G021 and 96W801H109) for supporting this research financially.

\section{References}

1. Karas, M.; Bachmann, D.; Hillenkamp, F. Influence of the Wavelength in High-Irradiance Ultraviolet Laser Desorption Mass Spectrometry of Organic Molecules. Anal. Chem. 1985, 57, 2935-2939.

2. Karas, M.; Hillenkamp, F. Laser Desorption Ionization of Proteins with Molecular Masses Exceeding 10,000 Daltons. Anal. Chem. 1988, 60, 2299-2301.

3. Tanaka, M.; Waki, H.; Ido, Y.; Akita, S.; Yoshida, T. Protein and Polymer Analyses up to $\mathrm{m} / \mathrm{z} 100,000$ by Laser Ionization Time-of-Flight Mass Spectrometry. Rapid Commun. Mass Spectrom. 1988, 2, 151-153.

4. Sunner, J.; Dratz, E.; Chen, Y.-C. Graphite Surface-Assisted Laser Desorption/Ionization Time-of-Flight Mass Spectrometry of Peptides and Proteins from Liquid Solutions. Anal. Chem. 1995, 67, 4335-4342.

5. Chen, Y.-C.; Shiea, J.; Sunner, J. Thin-Layer Chromatography-Mass Spectrometry Using Activated Carbon, Surface-Assisted Laser Desorption/Ionization. J. Chromatogr. A. 1998, 826, 77-86.

6. Chen, Y.-C. In Situ Determination of Organic Reaction Products by Combining Thin Layer Chromatography with Surface-assisted Laser Desorption/Ionization Time-of-Flight Mass Spectrometry. Rapid Commun. Mass Spectrom. 1999, 13, 821-825.

7. Chen, Y.-C.; Tsai, M.-F. Using Surfactants to Enhance the Analyte Signals in Activated Carbon, Surface-Assisted Laser Desorption/Ionization (SALDI) Mass Spectrometry. J. Mass Spectrom. 2000, 35, 12781284.

8. Chen, Y.-C.; Tsai, M.-F. Sensitivity Enhancement for Nitrophenols Using Cationic Surfactant-Modified Activated Carbon for Solid-Phase Extraction Surface-Assisted Laser Desorption/Ionization Mass Spectrometry. Rapid Commun. Mass Spectrom. 2000, 14, 2300-2304.

9. Alimpiev, S.; Nikiforov S.; Karavanskii, V.; Minton T.; Sunner, J. On the Mechanism of Laser-Induced Desorption-Ionization of Organic Compounds from Etched Silicon and Carbon Surfaces. J. Chem. Phys. 2001, $115,1891-1901$.

10. Okuno, S.; Arakawa, R.; Okamoto, K.; Matsui, Y.; Seki, S.; Kozawa, T.; Tagawa, S.; Wada, Y. Requirements for Laser-Induced Desorption/ Ionization on Submicrometer Structures. Anal. Chem. 2005, 77, 53645369.

11. Chen, Y.-C.; Wu, J.-Y. Analysis of Small Organics on Planar Silica Surfaces Using Surface-Assisted Laser Desorption/Ionization Mass Spectrometry. Rapid Commun. Mass Spectrom. 2001, 15, 1899-1903.

12. Xu, S.; Li, Y.; Zou, H.; Qiz, J.; Guo, Z.; Guo, B. Carbon Nanotubes as Assisted Matrix for Laser Desorption/Ionization Time-of-Flight Mass Spectrometry. Anal. Chem. 2003, 75, 6191-6195.

13. Chen, W.-Y.; Wang, L.-S.; Chiu, H.-T.; Chen, Y.-C.; Lee, C.-Y. Carbon Nanotubes as Affinity Probes for Peptides and Proteins in MALDI MS Analysis. J. Am. Soc. Mass Spectrom. 2004, 15, 1629-1635.

14. Ren, S.-F.; Zhang, L.; Cheng, Z.-H.; Guo, Y.-L. Immobilized Carbon Nanotubes as Matrix for MALDI-TOF-MS Analysis: Applications to Neutral Small Carbohydrates. J. Am. Soc. Mass Spectrom. 2005, 16, 333-339.

15. Chen, W.-Y.; Chen, Y.-C. Reducing the Alkali Cation Adductions of Oligonucleotides Using Sol-Gel-Assisted Laser Desorption/Ionization Mass Spectrometry. Anal. Chem. 2003, 75, 4223-4228.

16. Chen, C.-T.; Chen, Y.-C. $\mathrm{Fe}_{3} \mathrm{O}_{4} / \mathrm{TiO}_{2}$ Core/Shell Nanoparticles as Affinity Probes for the Analysis of Phosphopeptides Using $\mathrm{TiO}_{2}$ Surface-Assisted Laser Desorption/Ionization Mass Spectrometry. Anal. Chem. 2005, 77, 5912-5919.

17. Dale, M. J.; Knochenumss, R.; Zenobi, R. Graphite/Liquid Mixed Matrices for Laser Desorption/Ionization Mass Spectrometry. Anal. Chem. 1996, 68, 3321-3329.
18. Dale, M. J.; Knochenumss, R.; Zenobi, R. Two-Phase Matrix-Assisted Laser Desorption/Ionization: Matrix Selection and Sample Pretreatment for Complex Anionic Analytes. Rapid Commun. Mass Spectrom. 1997, 11, 136-142.

19. Zhang, Q.; Zou, H.; Guo, Z.; Zhang, A. Z.; Chen, X.; Ni, J. MatrixAssisted Laser Desorption/Ionization Mass Spectrometry Using Porous Silicon and Silica Gel as Matrix. Rapid Commun. Mass Spectrom. 2001, 15 217-223.

20. Guo, Z.; Ganawi, A. A. A.; Liu, Q.; He, L. Nanomaterials in Mass Spectrometry Ionization and Prospects for Biological Application. Anal. Bioanal. Chem. 2006, 384, 584-592.

21. Kinumi, T.; Saisu, T.; Takayama, M.; Niwa, H. Matrix-Assisted Lase Desorption/Ionization Time-of-Flight Mass Spectrometry Using an Inorganic Particle Matrix for Small Molecule Analysis. J. Mass Spectrom. 2000, 35, 417-422.

22. Schürenberg, M.; Dreisewerd, K.; Hillenkamp, F. Laser Desorption/ Ionization Mass Spectrometry of Peptides and Proteins with Particle Suspension Matrixes. Anal. Chem. 1999, 71, 221-229.

23. McLean, J. A.; Stumpo, K. A.; Russell, D. H. Size-Selected $(2-10 \mathrm{~nm})$ Gold Nanoparticles for Matrix Assisted Laser Desorption Ionization of Peptides. J. Am. Chem. Soc. 2005, 127, 5304-5305.

24. Huang, Y.-F.; Chang, H.-T. Nile Red-Adsorbed Gold Nanoparticle Matrixes for Determining Aminothiols through Surface-Assisted Laser Desorption/Ionization Mass Spectrometry. Anal. Chem. 2006, 78, 14851493.

25. Su, C.-L.; Tseng, W.-L. Gold Nanoparticles as Assisted Matrix for Determining Neutral Small Carbohydrates through Laser Desorption/ Ionization Time-of-Flight Mass Spectrometry. Anal. Chem. 2007, 79, 1626-1633.

26. Wei, J.; Buriak, J. M.; Siuzdak, G. Desorption-Ionization Mass Spectrometry on Porous Silicon. Nature 1999, 399, 243-246.

27. Lin, Y.-S.; Chen, Y.-C. Laser Desorption/Ionization Time-of-Flight Mass Spectrometry on Sol-Gel-Derived 2,5-Dihydroxybenzoic Acid Film. Anal. Chem. 2002, 74, 5793-5798.

28. Teng, C.-H.; Chen, Y.-C. Fiber Introduction Mass Spectrometry: Coupling Solid-Phase Microextraction with Sol-Gel-Assisted Laser Desorption/Ionization Time-of-Flight Mass Spectrometry. Rapid Commun. Mass Spectrom. 2003, 17, 1092-1094

29. Ho, K.-C.; Lin, Y.-S.; Chen, Y.-C. Laser Desorption/Ionization Mass Spectrometry on Sol-Gel-derived Dihydroxybenzoic Acid Isomeric Films. Rapid Commun. Mass Spectrom. 2003, 17, 2683-2687.

30. Lin, Y.-S.; Yang, C.-H.; Chen, Y.-C. Glass-Chip-Based Sample Preparation and On-Chip Tryptic Digestion for Matrix-Assisted Laser Desorption/Ionization Mass Spectrometric Analysis Using a Sol-Gel/ 2,5-Dihydroxybenzoic Acid Hybrid Matrix. Rapid Commun. Mass Spectrom. 2004, 18, 313-318.

31. Chen, C.-T.; Chen, Y.-C. Molecularly Imprinted $\mathrm{TiO}_{2}$-Matrix-Assisted Laser Desorption/Ionization Mass Spectrometry for Selectively Detecting $\alpha$-Cyclodextrin. Anal. Chem. 2004, 76, 1453-1457.

32. Chen, C.-T.; Chen, Y.-C. Desorption/Ionization Mass Spectrometry on Nanocrystalline Titania Sol-Gel-Deposited Films. Rapid Commun. Mass Spectrom. 2004, 18, 1956-1964.

33. Kaneco, S.; Chen, Y.; Westerhoff, P.; Crittenden, J. C. Fabrication of Uniform Size Titanium Oxide Nanotubes: Impact of Current Density and Solution Conditions. Scripta Mater. 2007, 56, 373-376.

34. Wu, H.-P.; Su, C.-L.; Chang, H.-C.; Tseng, W.-L. Sample-First preparation: A Method for Surface-Assisted Laser Desorption/Ionization Timeof-Flight Mass Spectrometry Analysis of Cyclic Oligosaccharides. Anal. Chem. 2007, 79, 6215-6221.

35. Finkel, N. H.; Prevo, B. G.; Velev, O. D.; He, L. Ordered Silicon Nanocavity Arrays in Surface-Assisted Desorption/Ionization Mass Spectrometry. Anal. Chem. 2005, 77, 1088-1095.

36. Hoang, T. T.; Chen, Y. F.; May, S. W.; Browner, R. F. Analysis of Organoselenium Compounds in Human Urine Using Active Carbon and Chemically Modified Silica Sol-Gel Surface-Assisted Laser Desorption/Ionization High-Resolution Time-of-Flight Mass Spectrometry. Anal. Chem. 2004, 76, 2062-2070.

37. Alimpiev, S.; Grechnikov, A.; Sunner, J.; Karavanskii, V.; Simanovsky, Y.; Zhabin, S.; Nikiforov, S. On the Role of Defects and Surface Chemistry for Surface-Assisted Laser Desorption Ionization from Silicon. J. Chem. Phys. 2008, 128, 014711-19.

38. Han, M.; Sunner, J. An Activated Carbon Substrate Surface for Laser Desorption Mass Spectrometry. J. Am. Soc. Mass Spectrom. 2000, 11 644-649.

39. Go, E. P.; Apon, J. V · Luo, G.; Saghatelian, A.; Daniels, R. H.; Sahi, V. Dubrow, R.; Cravatt, B. F.; Vertes, A.; Siuzdak, G. Desorption/Ionization on Silicon Nanowires. Anal. Chem. 2005, 77, 1641-1646.

40. Lee, W.-J.; Alhoshan, M.; Smyrl, W. H. Titanium Dioxide Nanotube Arrays Fabricated by Anodizing Processes-Electrochemical Properties. J. Electrochem. Soc. 2006, 153, B499-B505.

41. Northen, T. R.; Yanes, O.; Northen, M. T.; Marrinucci, D.; Uritboonthai, W.; Apon, J.; Golledge, S. L.; Nordström, A.; Siuzdak, G. Clathrate Nanostructures for Mass Spectrometry. Nature 2007, 449, 1033-1036.

42. Foster, D. W. Diabetes Mellitus. In Harrison's Principles of Internal Medicine, 14th ed.; Kasper, D. L.; Braunwald, E.; Fauci, A.; Hauser, S.; Longo, D.; Jameson, J. L., Eds.; McGraw-Hill: New York. 1998; p. 2060. 